\title{
Racismo, traumático e desmentido: aproximações entre Freud, Ferenczi e Grada Kilomba
}

\author{
Racism, traumatic and Disavowal: approximations \\ between Freud, Ferenczi and Grada Kilomba
}

\section{Luciana Maccari Lara', Andréa Mongeló', Jaqueline Batista ${ }^{3}$, Jordan Maia Nunes da Silva ${ }^{4}$, Silvana da Silva Henzel ${ }^{5}$ e Vitoria Justin dos Santos}

Resumo: A cultura, enquanto produtora de subjetividades, especialmentena contemporaneidade, tem colaborado para estimular novas e antigas formas de sofrimento psíquico dos sujeitos, especialmente para com a população negra. Durante o processo de escrita deste trabalho nos deparamos com as seguintes perguntas: Como pensar o contexto em que vivemos? Que questionamentos são oriundos do nosso tempo e quais deles fazemos a nós mesmos? Quantos analisandos negros estiveram ou estão conosco em nossos consultórios? Quantos colegas negros tivemos em nossas formações? E como se deu, ou não, a escuta desses sujeitos? Diante deste cenário, a psicanálise se faz cada vez mais necessária e é convocada a pensar e fazer refletir sobre o tema do racismo, fortemente atravessado por questões culturais, cujos reflexos incidirão diretamente na vida dos sujeitos e muitas vezes aparecerão na clínica psicanalítica. O presente artigo trata-se de uma revisão bibliográfica e tem como objetivo promover uma aproximação entre os conceitos de trauma pensado por Freud, desmentido/ desautorização de Ferenczi e racismo cotidiano de
Grada Kilomba, a fim de compreendermos a violência presente na cultura através de um saber eurocêntrico, branco e masculino.

\section{Palavras-chave: Racismo; Traumático; Desmentido.}

Abstract: Culture, as a producer of subjectivities, especially in contemporary times, has collaborated to stimulate new and old forms of psychic suffering for individuals, especially towards the black population. During the writing process of this work, we were faced with the following questions: how to think about the context in which we live? What questions come from our time and which ones do we ask ourselves? How many black analysands have been or are with us in our offices? How many black colleagues did we have in our formation processes? And did the listening process of these subjects happen or did not happen? Faced with this scenario, psychoanalysis has become increasingly necessary and is called upon to think about and reflect on the theme of racism, strongly crossed by cultural issues, whose reflexes will directly affect the subjects'

\footnotetext{
1 Psicóloga. Psicanalista. Mestre em Filosofia. Membro Pleno da Sigmund Freud Associação Psicanalítica. E-mail: lucianamlara@gmail.com

2 Psicóloga. Psicanalista. Membro Efetivo da Sigmund Freud Associação Psicanalítica. E-mail: abcmongelo@hotmail.com

3 Acadêmica em Psicologia. Pós-Graduanda em Psicologia Fenomenológica Existencial Humanista.

E-mail: jackbatistasilva@gmail.com

${ }^{4}$ Acadêmico em Psicologia. Bolsista de Iniciação Científica pelo NUPPEC. E-mail: jordan.alemanha@gmail.com

5 Psicóloga. Psicanalista. Membro Efetivo da Sigmund Freud Associação Psicanalítica. Especialista em Cuidado Materno Infantil. Membro da Sociedade de Psicologia do RS. E-mail: silvanahenzel@gmail.com

6 Psicóloga. Pós-Graduada em Psicanálise pela Universidade do Vale do Rio dos Sinos (UNISINOS).

E-mail: vitoria.justin@hotmail.com
} 
lives and will often appear in the psychoanalytic clinic. This article is a bibliographic review and aims to promote an approximation between the concepts of trauma thought by Freud, denial/disallowance of

\section{Introdução}

A contemporaneidade, cada vez mais, exige da psicanálise e dos psicanalistas uma leitura do sofrimento para além da dimensão intrapsíquica. Gondar (2012) evoca a afirmação com que 0 historiador Eric Hobsbawm inicia sua obra "A era dos Extremos" (1995): vivemos a era dos eventos traumáticos, do qual todos somos sobreviventes, vítimas e perpetradores. A autora aponta ainda o fato de que boa parte da filosofia ocidental do século $X X$-e, podemos acrescentar, também deste início do século XXI - se ocupou e ainda se ocupa de construir conceitos que deem conta da força do trauma na contemporaneidade.

0 agora centenário artigo freudiano Além do Princípio do Prazer (Freud, 1920-1976), escrito a partir da experiência de escuta do sofrimento, sem possibilidade de representação, dos soldados vindos do front da $1^{\text {a Guerra }}$ Mundial, certamente integra o esforço de construção teórica encetado como resposta ao trauma e seus efeitos de (des)subjetivação. Posteriormente, em Mal estar na cultura, Freud (1930-1976), apontava ainda que uma das fontes de sofrimento do sujeito tem origem na sua relação com o outro. Portanto, o sofrimento psíquico vivido pelo indivíduo não pode ser dissociado de seu contexto intersubjetivo e cultural.

É nesse cenário que a psicanálise vem sendo convocada a refletir sobre 0 tema do racismo, que atravessa questões culturais e também marca sua passagem nas reflexões sobre a clínica psicanalítica. Ainda que seja inegável o desenvolvimento e a transformação da psicanálise, como teoria e método, a partir das interrogações deixadas por Freud e do trabalho dos autores pós-freudiano, o racismo representa um desafio para um campo de saber que nasceu e se desenvolveu em um contexto eurocêntrico, branco e masculino. E hoje, em que contexto vivemos? Quais os questionamentos que nosso tempo nos dirige e que fazemos a nós mesmos? A fim de que a psicanálise siga vigente em sua potência para fazer frente ao sofrimento contemporâneo, algumas questões se impõem cada vez mais: quantos analisandos negros estão ou estiveram conosco em nossos consultórios? Ou em nossas formações? E como se deu, ou não se deu, a escuta desses sujeitos? Essas são perguntas essenciais nesse momento.

É no sentido da contemporânea convocação dirigida à psicanálise, de que ela seja um instrumento para compreender os modos de sofrimento originados nas relações intersubjetivas, para além do intrapsíquico, que este trabalho pretende promover uma aproximação entre os conceitos de trauma, como postulado por Freud, desmentido/desautorização em Ferenczi e racismo cotidiano em Grada Kilomba.

\section{Método}

0 presente artigo trata-se de uma revisão bibliográfica sobre o tema do racismo, traumático e desmentido, pelo viés da teoria psicanalítica. Para Gil (2008), a revisão bibliográfica refere-se a uma pesquisa "desenvolvida a
Ferenczi, and everyday racism by Grada Kilomba, in order to understand the violence present in culture through white, masculine and Eurocentric knowledge.

Keywords: Racism; Traumatic; Denial.

partir de material já elaborado, constituído principalmente de livros e artigos científicos" (Gil, 2008, p. 50). Para tanto, foram utilizados artigos e livros impressos, alguns textos clássicos de Sigmund Freud e também textos de autores pós-freudianos, a fim de melhor compreendermos a temática estudada.

\section{Racismo cotidiano: o traumático que define sujeitos e objetos}

Memórias da Plantação, livro publicado originalmente em inglês, resultado da tese de doutoramento da autora portuguesa Grada Kilomba, é um percorrido preciso e contundente sobre como a colonização é um processo que, longe de ter encerrado - como pretende 0 assim declarado fim das políticas e estados coloniais -, está profundamente estabelecido e enraizado na forma como se constituem as subjetividades de negros e brancos, com consequências extensamente concretas. Nessa obra, Grada Kilomba propõe, ao Iado dos conceitos já conhecidos de racismo institucional e racismo estrutural, o conceito de "racismo cotidiano":

0 racismo cotidiano refere-se a todo vocabulário, discursos, imagens, gestos, ações e olhares que colocam o sujeito negro e as Pessoas de Cor, não só como o "Outra/o" - a diferença contra a qual 0 sujeito branco é medido - mas também como Outridade, isto é, como a personificação dos aspectos reprimidos na sociedade branca. Toda vez que sou colocado como "outra" - seja a "outra" indesejada, a "outra" intrusa, a "outra"violenta, a "outra"passional, seja a "outra" suja, a "outra" excitada, a "outra" selvagem, a "outra" natural, a "outra" exótica - estou inevitavelmente experienciando o racismo, pois estou sendo forçada a me tornar a personificação daquilo com o que o sujeito branco não quer ser reconhecido. Eu me torno a/o "Outra/o"da branquitude, não o eu - e, portanto, a mim é negado o direito de existir como igual (Kilomba, 2019, p. 78).

A autora aponta que, a projeção sobre 0 sujeito negro, diz respeito especialmente a conteúdos agressivos e sexuais e enumera algumas figuras pelas quais esse mecanismo se manifesta: infantilização, primitivização, incivilização, animalização, erotização. Acrescenta ainda que o termo "cotidiano" procura situar que essas experiências não são pontuais, mas constituem uma "constelação de experiências da vida que se repetem constantemente ao longo da biografia de alguém", em todos os âmbitos: ser monitorado pela polícia no transporte público, ser encarado fixamente na rua, ser ultrapassado por uma pessoa branca numa fila, ser questionado sobre uma suposta condição de estrangeiro no próprio país.

Kilomba (2019) define sujeitos como aqueles que têm a possibilidade 
de definir suas realidades, estabelecer suas identidades e nomear suas histórias. Citando Hooks (1989) citado em Kilomba (2019) afirma que ser objeto significa, ao contrário, ser falado, definido e estabelecido em sua realidade, identidade e história, por alguém que é sujeito.

A constelação de experiências que compõem o racismo cotidiano constitui, em diferentes perspectivas, a condição que Kilomba descreve como passar a vida "sendo falada", ou seja, posicionada no lugar de objeto. Desde vivências infantis violentas, como a de ser colocada no lugar de empregada doméstica pelo médico a quem foi consultar, passando pelas relações afetivas e sexuais, profissionais e acadêmicas, a experiência de "ser falada" pelo outro branco reduz sistematicamente o sujeito negro à condição de objeto. Citando Hooks (1989) citado em Kilomba (2019) define sujeitos como aqueles que têm a possibilidade de definir suas realidades, estabelecer suas identidades e nomear suas histórias. Ser objeto significa, ao contrário, ser falado, definido e estabelecido em sua realidade, identidade e história, por al guém que é sujeito.

A objetificação descrita por Kilomba (2019) nos remete ao efeito do traumático. 0 conceito de trauma ocupa um lugar central na teoria psicanalítica, sendo desde o início um dos fatores etiológicos da neurose. Nesta primeira perspectiva, sublinhando o que denominou teoria econômica, Freud teoriza um modelo etiológico da histeria em que um acontecimento externo impõe ao aparelho psíquico um afluxo excessivo de energia: a fim de controlar tal afluxo, o psiquismo é lançado num funcionamento segundo o processo primário. 0 trauma é, então, descrito por Freud (1895-1996) como um acontecimento que inclui dois tempos: no caso Emma, a primeira cena - em que ela é tocada por baixo da roupa pelo comerciante - é ressignificada pela segunda cena quando, num momento posterior do desenvolvimento da sexualidade, 0 riso dos rapazes na loja toma uma conotação claramente sexual, na medida em que ela então pode identificar a sua própria excitação. 0 despreparo do psiquismo para registrar o primeiro acontecimento determina que, na ocorrência da segunda cena, não exista possibilidade de lidar com a excitação, 0 que determina 0 efeito traumático.

0 acontecimento traumático, a princípio descrito como tendo origem externa, tem sua força de ação gradativamente relacionada ao mundo interno do paciente. A origem externa do acontecimento traumático perde gradativamente sua força na teoria freudiana, enquanto sua origem interna - a efetividade da vida fantasística do sujeito em conferir intensidade aos acontecimentos de origem interna - cresce em importância no que diz respeito à etiologia da neurose. Esta posição consolida-se na afirmação de Freud, na Carta 69 a Fliess datada de 21/09/1897 - "Não acredito mais em minha neurótica" (Freud, 1897-1996, p. 315) - referindo-se à modificação na teoria etiológica da neurose, que substituiu naquele momento a teoria da sedução pelo papel da vida interna e da fantasia. Por um longo período, até a chamada "virada de 20", a construção freudiana giraria em torno da sexualidade infantil, da fantasia, do recalcamento destas e do conflito psíquico decorrente deste processo.

Com a $1^{\mathrm{a}}$ Guerra Mundial, e o surgimento do peculiar sofrimento dos soldados que dela regressavam, a força do evento externo sobre o psiquismo volta a ocupar os pensamentos e as elaborações de Freud. Os sonhos de repetição destes soldados, em que as cenas da guerra voltavam uma e outra vez com intensidade igual à do acontecimento, puseram em questão a ideia de Freud do sonho como ativação do circuito psíquico que leva à realização do desejo através da ativação da fantasia, de acordo com o princípio do prazer. Havia algo nestes sonhos que se encontrava além do princípio do prazer - além, portanto, da dimensão do desejo e do estatuto do sujeito. A invasão do aparelho psíquico pelo excesso impõe ao aparelho a tarefa de controlá-lo, extinguindo a possibilidade de permanecer dentro do circuito do desejo - desejo entendido como 0 circuito desenhado no psiquismo pela ação específica - a ação do objeto que propicia a descarga adequada à ação específica. Assim, 0 desenvolvimento da teoria psicanalítica percorre caminhos que permitem pensar o traumático para além da dimensão intrapsíquica (Freud, 1920-1976).

É esta concepção de traumático que permite a aproximação ao que Kilomba define como a condição do sujeito negro, quando é arrancado da posição de sujeito pela invasão da fala branca que o define. Ao explicar 0 título do livro Memórias da Plantação, Kilomba afirma que o mesmo aponta para 0 choque violento que incide sobre o sujeito negro quando, súbita e estranhamente, é lançado de volta à condição de escravizado no cenário da plantation. A autora ilustra um desses momentos com uma história pessoal. Aos 13 anos, tendo ido consultar um médico em razão de uma gripe, escutou dele a seguinte proposta: que o acompanhasse e à sua família - mulher e dois filhos já adultos - à praia, para uma casa alugada para as férias familiares. Lá ela teria bastante tempo para si, para ir à praia e "fazer o que quisesse". A condição era que cozinhasse as refeições, limpasse a casa e eventualmente lavasse algumas roupas. Kilomba (2019) descreve sua reação:

Olhei para ele calada. Eu realmente não sei se fui capaz de dizer algo. Acho que não. Mas me lembro de sair do consultório num estado de vertigem e de vomitar, após ter me distanciado de lá algumas ruas, antes de chegar em casa. Estava diante de algo irracional (Kilomba, 2019, p. 93).

A jovem menina é repentinamente transformada em servente, a relação médico-paciente se transforma em relação senhor-servente. A destituição da condição de sujeito da menina negra pelo médico branco, tem um caráter de não reconhecimento de uma realidade percebida. A menina continua sendo uma criança e também a paciente: não obstante, o médico passa ao largo de sua própria percepção e invade o psiquismo da menina com uma cena em que ela é uma servente e não mais a paciente criança. Como efeito da invasão violenta, a menina perde sua condição de falar: impossibilitada a representação, a descarga do excesso faz-se pela via somática. E ela vomita.

Em Esboço de Psicanálise, Freud (1940-1976) complexiza o entendimento sobre o trauma, enfatizando seu caráter não absoluto, e descrevendo-0 como resultado de uma relação entre a intensidade do estímulo aplicado e a complexidade do organismo sobre o qual ele incide:

0 dano infligido ao ego por suas primeiras experiências dá-nos a impressão de ser desproporcionalmente grande, mas podemos fazer uma analogia com as diferenças dos resultados produzidos pela picada de uma agulha numa massa de células no ato da divisão celular (como nas experiências de Roux) e no animal crescido que se desenvolveu a partir delas (Freud, 1940-1976, p. 197).

Ao utilizar a metáfora do embrião atingido pela agulha, Freud sublinha e enfatiza o fator "vulnerabilidade do aparelho psíquico" como fator determinante do efeito traumático de um evento. Nessa perspectiva, as elaborações 
de Figueiredo (2008) ampliam a compreensão sobre o que significa o estado de vulnerabilidade que potencializa o efeito do evento traumático. 0 autor entende que o traumático não consiste apenas no excesso provindo da realidade, mas também do resultado da falta de experiências de compartilhamento que permitiriam a inscrição psíquica do excesso. Afirma 0 autor:

Não se trataria, portanto, apenas de ser "muito afetado", mas de não encontrar uma resposta social capaz de conter e processar simbolicamente as intensidades afetivas. Cria-se então uma área de experiência carente de representação compartilhada. São esses afetos não suportados e, portanto, insuportáveis, os que podem produzir efeitos traumatizantes, desintegrantes e mortíferos (Figueiredo, 2008, p. 21).

Para Figueiredo (2008), portanto, a vulnerabilidade que predispõe 0 aparelho psíquico ao trauma não se deve apenas a uma condição interna ou de momento evolutivo, mas das condições do contexto que envolve este aparelho, e de suas condições para compartilhar e reconhecer experiências excessivas, permitindo assim sua inscrição e representação. Isso nos permite afirmar que o racismo cotidiano, operando pela via de falar o outro negro sem reconhecer sua condição de falar por si mesmo, subtrai exatamente a possibilidade de experiência compartilhada que permitiria a representação do excesso. 0 racismo cotidiano pode, assim, ser definido como um conjunto de elementos de violência contínua não representada, constituindo-se como fonte e expressão contemporânea do traumático.

0 racismo cotidiano de Kilomba (2019) fala de eventos que, numa leitura rápida, não seriam incluídos na categoria de traumáticos, por sua condição corriqueira e, justamente, cotidiana. No entanto, a complexização feita por Freud (1940-1976) no Esboço, dando conta da vulnerabilidade como fator que predispõe o aparelho ao trauma, assim como a leitura de Figueiredo (2008), que evoca as condições externas de compartilhamento e reconhecimento do estatuto excessivo de uma experiência - considerando que a possibilidade de compartilhamento através da linguagem é essencial à possibilidade de representação da experiência excessiva - auxilia na compreensão racismo cotidiano como um evento traumático. Veremos a seguir como o conceito ferencziano de desmentido também é essencial para tal compreensão.

\section{Racismo e desmentido: o que pode ser falado e escutado?}

0 racismo, e de forma particular o racismo cotidiano, possui efeito de determinação sobre o que pode ou não ingressar na linguagem. Sobre isso, Kilomba (2019) afirma:

Falar torna-se, assim, virtualmente impossível, pois, quando falamos, nosso discurso é frequentemente interpretado como uma versão dúbia da realidade, não imperativa o suficiente para ser dita, nem tampouco ouvida. Tal impossibilidade ilustra como 0 falar e o silenciar emergem como um projeto análogo. 0 ato de falar é como uma negociação entre quem fala e quem escuta, isto é, entre falantes e suas/seus interlocutoras/es (Castro Varela e Dhawan, 2003). Ouvir é, nesse sentido, 0 ato de autorização em direção à/ao falante. Alguém pode falar (somente) quando sua voz é ouvida. Nessa dialética, aquelas/es que são ouvidas/os são também aquelas/es que "pertencem". E aquelas/es que não são ouvidas/os são também aquelas/es que "não pertencem". (Kilomba, 2019, p. 42).

0 acordo sobre 0 que pode ser falado, sobre quais intensidades podem ser transformadas em palavras, e, portanto, representadas, não é um acordo entre iguais, mas está atravessado pela hegemonia do discurso do branco. Se a fala negra é desconstituída e desautorizada, e se a possibilidade de ter lugar nesse acordo entre falantes é a via pela qual se constrói um sujeito, só podemos concluir que um sujeito negro é um sujeito que se constitui pela via da destituição, à revelia do acordo hegemônico, remando contra a maré. Eque essa constituição subjetiva, sempre às voltas com o que não pode constituir-se, porque não encontra autorização para se colocar na linguagem, é atravessada pelo traumático, vetor do desligado e da compulsão à repetição. Aqui, tudo aquilo que não encontra palavras para se fazer falar, para tornar-se passado, segue sempre sendo presente, doendo, insistindo e repetindo.

0 caráter traumático da destituição da fala encontra sua melhor definição em Ferenczi (1931-1986), que propõe o traumático como efeito da verleugnung. Esse mecanismo cujo nome original recebeu diferentes traduções - recusa, renegação, desmentida, desautorização (da percepção) - foi definitivamente cunhado por Freud (1927-1996) em OFetichismo e desenvolvido ao longo de trabalhos posteriores, em especial em A Divisão do Ego no Processo de Defesa (Freud, 1940-1996) e Esboço de Psicanálise (Freud, 1940-1976). Trata-se da reação do psiquismo infantil à percepção da ausência de pênis na mulher, ou seja, à castração. Partindo da compreensão do objeto fetiche como um substituto do pênis materno "perdido", Freud vai construindo a premissa de que, nesse tipo de estruturação, duas correntes paralelas coexistem na consciência - uma que rejeita e outra que não pode deixar de reconhecer a percepção da castração - e que a sustentação desse mecanismo se sustenta numa espécie de divisão do ego. Segundo a definição de Laplanche e Pontalis (1997), a verleugnung consiste na recusa em reconhecer a realidade de uma percepção traumatizante - em última análise, a percepção da ausência de pênis na mulher que, por razões singulares, tornou-se excessiva e traumática.

Ferenczi (1931-1986) introduz uma perspectiva absolutamente nova de leitura do trauma e a novidade de sua leitura está na articulação que realiza entre 0 trauma e a verleugnung. Gondar (2012) afirma que o ineditismo da leitura do trauma por Ferenczi não está, como comumente se afirma, no fato de que ele apontava a realidade do trauma, enquanto Freud privilegiava a realidade psíquica e a realidade infantil. Ressalta a autora: "Para Ferenczi, 0 traumático não está na ocorrência de um evento e nem mesmo no seu grau de violência, mas sim em algo que pode se dar - ou não - em um segundo tempo. A originalidade de Ferenczi consiste em atribuir ao desmentido (verleugnung) a existência do trauma"'(Gondar, 2012, p. 195-196).

Para Ferenczi (1931-1986), a verleugnung é o elemento efetivamente gerador do traumático. Na tradução brasileira de suas obras para o português, o termo usado foi negação. Como vemos em seu artigo "Análise de crianças com adultos": "0 pior é realmente a negação, a afirmação de que não aconteceu nada, de que não houve sofrimento, ou até mesmo ser espancado e 
repreendido quando se manifesta a paralisia traumática dos pensamentos ou dos movimentos; é isso sobretudo, o que torna o traumatismo patogênico" (Ferenczi, 1931-1986, p. 79).

Encontramos em Figueiredo (2003) o termo que melhor traduz o efeito traumático, a que Ferenczi se refere, que é a desautorização. Desautorizar reflete melhor, para o autor, o que se passa no psiquismo do sujeito. Uma desautorização de percepção, que desapropria o sujeito dele mesmo e aí sim abre caminho para a fixação dos efeitos nocivos do evento traumático.

Kuppermann (2019) faz ainda uma diferença entre o desmentido e 0 desautorizado, caracterizando o segundo como referente aos processos intrapsíquicos que são vividos por quem sofreu o trauma, que passa a duvidar de suas percepções. Temos, então, com esses dois conceitos articulados, os personagens da cena: aquele que inflige o racismo cotidiano e usa o mecanismo do desmentido, da recusa, e o sujeito que sofre o racismo e que, em seu psiquismo, experimenta o efeito do desautorizado, o sujeito desapropriado de si mesmo.

Kilomba dá voz a sua entrevistada Alicia, que protagoniza a seguinte passagem:

Bom, uma vez essa mulher - nós estudamos juntas e ficamos amigas mesmo depois da escola -, e um belo dia tivemos essa conversa sobre pessoas negras e eu disse a ela como é ser negra aqui (na Alemanha) e não é fácil para mim ser sempre a única negra. E ela disse: "Bom, mas para mim você não é negra. Eu não acho que você seja negra! Eu até esqueço que você é negra!"e. . . e ela disse aquilo como se estivesse me fazendo um favor. Mas EU SOU NEGRA! Isso era o que a minha mãe adotiva fazia todo o tempo, negava que nós éramos crianças negras, eu e meu irmão. Ela não dizia nada, ela nunca disse uma palavra . . nós nunca conversamos sobre isso quando eu era pequena (Kilomba, 2019, p. 145).

Sobre essa passagem, Kilomba (2019) cita Laplanche e Pontalis (1988) para ressaltar que, em alemão, o termo verneinung (negação, como em "Você não é negra") possui dois sentidos. Um deles é o de negação gramatical ou lógica, e o outro é o que, por referir-se à recusa da realidade, aproxima-se da verleugnung. Na narrativa de Alicia ficam claras as duas posições discriminadas por Kupermann em relação ao mecanismo da verleugnug. A amiga se defende do fato de que as diferenças entre negros e brancos existem e são frutos da discriminação, recusando a própria percepção da negritude de Alicia: enquanto isto, a reação de Alicia - "Mas EU SOU NEGRA!" - aponta para a necessidade de auto reafirmação diante da desautorização promovida pelo desmentido da amiga.

De acordo com Kupermann (2019), o circuito da traumatogênese ferencziana pode ser entendido em três momentos: o ponto inicial de todo padecimento psíquico seria o rompimento de modo brutal e indecifrável do vínculo amoroso intenso de uma criança com um adulto, sendo esta uma forte violação sofrida. 0 primeiro momento do evento traumático, portanto, é a agressão realizada por parte do adulto. Tal evento é incompreensível para a criança, que é incapaz de nomear sua dor, esse momento é denominado como o tempo do indizível. 0 segundo momento do trauma ocorre quando a criança violentada busca outro adulto cuja relação de confiança tenha sido estabelecida, a fim de fazê-lo o destinatário do seu padecimento inominável, de modo a que, com sua ajuda, consiga simbolizá-lo e dar conta. Esse segundo momento é denominado de tempo do testemunho. E por fim, o último tempo que completa o circuito do trauma é o tempo do desmentido, tempo esse que abandona o sujeito violado, o sujeito é mantido enclausurado, impossibilitado de dizer, de falar da sua dor frente a dor que Ihe foi causada.

Podemos observar o circuito da traumatogênese ferencziana, descrito por Kupermann (2019), em outra cena narrada a Kilomba (2019) pela entrevistada Alicia:

Eu realmente odiava quando as pessoas tocavam o meu cabelo:'que cabelo lindo! Ah, que cabelo interessante! Olha, cabelo afro . . 'E 0 tocavam. Eu me sentia como um cachorro sendo acariciado...como um cachorro que está sendo tocado. E eu não sou um cachorro, sou uma pessoa. E [quando eu era criança] minha mãe nunca lhe dizia para parar, embora eu tivesse explicado para ela que eu não gostava daquilo. Mas ela não conseguia entender por que eu não gostava: 'Sim, mas seu cabelo é diferente e as pessoas só estão curiosas!". Ela não entendia por que eu não gostava (...) Eu nunca tocaria o cabelo de al guém daquela forma, do nada! Quero dizer... como alguém pode fazer isso... (Kilomba, 2019, p. 121).

Na cena, a menina é fisicamente invadida pelo toque de desconhecidos em seu cabelo, e psiquicamente invadida pela denominação "diferente;/interessante", provinda de outros, possivelmente adultos, e certamente ocupando uma posição de hegemonia branca em relação a ela. "Você é interessante, você é diferente". Embora Alicia dissesse à mãe que não gostava daquilo, certamente sem poder definir exatamente o por que - justamente pelo caráter da agressão traumática, que excede as palavras - sua reclamação não encontra eco. Encontra, no entanto, aquilo que Kupermann (2019) nomeia como 0 terceiro momento do circuito da traumatogênese em Ferenczi: o desmentido propriamente dito, quando a mãe afirma: "Sim, mas seu cabelo é diferente, as pessoas só estão curiosas". Kilomba (2019) afirma ainda ser o comentário da mãe um lembrete para Alicia: mesmo numa relação mãe-filha, o ponto de vista de uma mulher negra é menos válido do que o ponto de vista de uma mulher branca. A despeito das palavras de Alicia, quem define o que importa ou não é sua mãe branca.

Podemos constatar, dessa forma, a fecundidade da relação ferencziana entre trauma e desmentido para a compreensão dos efeitos do racismo cotidiano. Isso se deve, como aponta Gondar (2012) pela ênfase dada por Ferenczi, às relações de poder, ao invés dos personagens dessas relações e também ao seu entendimento de que o desmentido incide não sobre 0 evento, mas sobre o próprio sujeito. Podemos, com isto, retomar a definição de sujeito proposta por Kilomba (2019) - sujeito é aquele que fala, objeto é aquele que é falado - para compreender de que forma o racismo cotidiano, que se manifesta na forma de um desmentido, tem como efeito a desautorização da percepção e da fala do sujeito negro sobre si própria. Invadido, assim, pelo desmentido que a fala branca representa, o sujeito negro é continuamente exposto à invasão traumática desta fala, e reduzido à condição de objeto aquele que é falado pelo outro. 


\section{Considerações finais}

0 fato de desconhecermos profundamente nossa história escravocrata, os apagamentos que ela produziu e os efeitos desse apagamento em nossa sociedade, atua como um verdadeiro desmentido, tal como Ferenczi o definiu. Temos, então, outra camada do traumático: ao não conseguirmos escutar a especificidade da dor produzida por esse contexto, certamente reproduzimos 0 desmentido e a violência.

Por que somente agora nos questionamos a respeito das perguntas mencionadas nos parágrafos iniciais deste texto? 0 fato de termos vivido até o presente momento em nossa prática clínica sem nos ocuparmos com esse desmentido, para buscar entendê-lo ou até mesmo na busca de outras possibilidades, coloca-nos, ou pode ter nos colocado, como perpetuadores desse aprisionamento traumático em que fica o sujeito ao ter sua dor desmentida? Considerar que o racismo é estrutural e cotidiano e que, como afirma a autora, mantém fixas as estruturas de poder e os sujeitos distantes da possibilidade de ocupar lugares de saber e poder, também é uma reflexão fundamental para nós, psicanalistas. Tais reflexões permitiram a necessária fundamentação da nossa prática para a escuta do sofrimento gerado por estas estruturas.

Neste sentido, as contribuiç̧ões de Ferenczi e o desenvolvimento de suas ideias pela psicanálise contemporânea revelam-se essenciais. Como observa Gondar (2012):

Ferenczi construiu este modelo (do trauma) a partir de histórias familiares que envolviam uma criança abusada. Contudo, este modelo não privilegia personagens, e sim relações. Relações de poder, de dependência, de desvalorização, de desrespeito; em suma, relações políticas, na mesma medida em que afetos como vulnerabilidade, ambivalência, humilhação e vergonha podem ser considerados, como propõe Homi Bhabha, afetos políticos (Bhabha, 1994). Poderia então a noção de desmentido ser aplicada em situações mais amplas, como as que dizem respeito a coletivos ou sociedades? E de que modo? (Gondar, 2012, p. 196).

A resposta é, sem dúvida, positiva. A centralidade do conceito de desmentido em Ferenczi (1931-1986), onde eleéo ponto de partida de uma visão da vulnerabilidade - termo usado por Gondar (2012), ao invés de desamparo, com o objetivo de enfatizar o caráter relacional da condição vulnerável, em oposição ao caráter intrínseco do desamparo - permite-nos ampliar o entendimento sobre a origem intersubjetiva e relacional do sofrimento psíquico, e alçar ainda mais a psicanálise à condição de instrumento fundamental para a construção teórica sobre os fenômenos sociais.

Por sua vez Kilomba (2019), para além de sua posição de psicanalista, lança mão da teoria psicanalítica em suas elaborações, colocando-se numa interessante posição de interlocutora da psicanálise. Suas ideias podem ser lidas como propostas ao campo psicanalítico, como interrogantes com potencial de disparar movimentos de elaboração teórica e técnica. Urge escutar os efeitos destes movimentos de (des)subjetivação e de desumanização, que a autora chama de "racismo cotidiano", e construir possibilidades de pensá-los metapsicologicamente, para fundamentar a escuta e a intervenção.
Nada pode estar mais incluído no campo da psicanálise do que 0 traumático dessubjetivante que, ao fim e ao cabo, e guardadas as imensas diferenças de efeito, incide sobre negros e brancos, na medida em que faz de todos menos sujeitos e mais resultado da repetição mortífera. E o sentido da psicanálise, como método de tratamento, pesquisa e como campo teórico, não poderia ser outro do que se ocupar daquilo que nos faz mais objetos e menos sujeitos. Não seria essa, inclusive, uma definição possível do trabalho psicanalítico?

Evidencia-se, a potência da psicanálise enquanto lugar de fala e escuta, como um lugar de acolhimento daquilo que éimpossível de suportar, daquilo que é da ordem do traumático. Além disso, a psicanálise se preocupa com a verdade do sujeito do inconsciente, e, portanto, através da sua prática, ela pode criar um setting capaz de fazer surgir um sujeito onde antes só havia um objeto, sujeito esse que foi dito e falado pelo saber branco, eurocêntrico e masculino. Espera-se ainda que a leitura deste artigo possa ampliar horizontes e faça surgir novas perguntas onde antes só haviam respostas, dar voz e lugar de fala aos sujeitos negros e buscar outras possibilidades frente ao racismo que é estrutural e cotidiano.

\section{Referências}

Ferenczi, S. ([1909-1933]1986). Análise de adultos com crianças. in: Ferenczi, S. Escritos psicanalíticos. Rio de Janeiro, Taurus.

Figueiredo, L. C. (2008). Psicanálise: elementos para uma clínica contemporânea. São Paulo: Escuta.

Freud, S. (1897-1996). Carta 69. In: Freud, S. Publicações Pré-Psicanalíticas e Esboços Inéditos. Obras completas. vol. 01, Rio de Janeiro: Imago, p. 315-317.

Freud, S. (1895-1996). Projeto para uma psicologia científica. In: Freud, S. Publicações Pré-psicanalíticas e Esboços Inéditos. Obras completas. vol. 01, Rio de Janeiro: Imago, p. 341-483.

Freud, S. (1920-1976). Além do princípio do prazer. Obras completas. vol. 18, Rio de Janeiro: Imago, p. 17-92.

Freud, S. (1927-1996). 0 Fetichismo. In: Freud, S. O futuro de uma ilusão, o Mal-Estar na Civilização e outros trabalhos. vol. 21, Rio de Janeiro: Imago, p. 155-159.

Freud, S. (1930-1976). O mal-estar na civilização. Obras completas. vol. 21, Rio de Janeiro: Imago, p. 81-78.

Freud, S. (1940-1976). Esboço de psicanálise. Obras completas. vol. 23, Rio de Janeiro: Imago, p. 168-237.

Freud, S. (1940-1996). A Divisão do Ego no Processo de Defesa. In: Freud, S. Moisés e o Monoteísmo, Esboço de Psicanálise e outros trabalhos. vol. 23, Rio de Janeiro: Imago, p. 287-289.

Gil, A. C. (2008). Métodos e Técnicas de Pesquisa Social. São Paulo: Atlas.

Gondar, Jô. (2012). Ferenczi como pensador político. Cadernos de psicanálise (Rio de Janeiro), 34(27), 193-210. Recuperado de http://pepsic.bvsalud.org/scielo.php?script=sci_arttext\&pi$d=\$ 1413-62952012000200011 \& \operatorname{lng}=p t \& t \operatorname{lng}=p t$.

Hooks, B. (1989). Talking Back: Thinking Feminist, Talking Black. Boston: South End Press. citado em Kilomba, G. (2019). Memórias da Plantação:episódios de racismo cotidiano. Rio de Janeiro: Editora Cobogó.

Kilomba, G. (2019). Memórias da Plantação: episódios de racismo cotidiano. Rio de Janeiro: Editora Cobogó.

Kupermann, D. (2019). Ferenczi e os objetivos do tratamento psicanalítico: autenticidade, neocatarse, crianceria. Estilos Da Clínica, 24 (2), 182-194. Recuperado de https://doi.org/10.11606/issn.1981-1624. v24i2p182-194 
Kupermann, D. (2019). Por que Ferenczi? Coleção Grandes Psicanalistas. Editora: Zagodoni, São Paulo.

Laplanche, J. \& Pontalis, J.-B. (1988). The Language of Psychoanalysis. London: Polestar Wheatons Ltd.

Laplanche, J. \& Pontalis, J.-B. (1997). Vocabulário da Psicanálise. São Paulo: Martins Fontes. (Trabalho original publicado em 1967) 